\title{
Temple Students Mount Response Against the COVID-19 Pandemic
}

\author{
VITTORIA BONI ${ }^{1}$; SCHYLER EDWARDS ${ }^{1}$; KURT KOEHLER ${ }^{1}$; MICHELE LIU2; THERESA \\ MCSHEA $^{2}$; MEGHAN SWYRYN 1 \\ ${ }^{1}$ Lewis Katz School of Medicine, Temple University \\ ${ }^{2}$ College of Public Health, Temple University \\ Correspondence: tug92139@,temple.edu (Vittoria Boni)
}

\section{Introduction}

During the COVID-19 pandemic, students of Temple University faced the challenges of academic stress, relocation, and fear for the spread of COVID-19, all of which have become well known to students across the U.S. While many students and faculty left campus due to the unchecked spread of COVID-19 in Philadelphia, others stayed behind to contribute to various pandemic relief projects. Temple University's central location in North Philadelphia grants students a unique opportunity to offer their training and resources to the residents of the community. One such effort is the Fabric Masks for North Philly (FMNP) project. The diverse student leadership team of FMNP has recruited students of various academic backgrounds from Temple University to work throughout the spring, summer, and fall months of the pandemic, delivering masks to our neighbors in North Philadelphia. Since the beginning of the project in April 2020, FMNP has supplied over 13,000 masks to the residents of North Philadelphia. This work could not have been accomplished without the hard work, generosity, and dedication of our maskmaking volunteers and the distributing organizations that continue to serve their communities during COVID-19. The purpose of this article is to discuss the mission of FMNP, the key players involved and progression of our work since its inception, and outcomes based on feedback from our community partners.

\section{Founding and Initial Vision}

Fabric Masks for North Philly is an initiative that started at Temple's Lewis Katz School of Medicine (LKSOM) in April 2020 amidst the COVID-19 pandemic. The project was created to provide volunteermade, protective face masks to North Philadelphia residents, particularly those at risk of adverse outcomes from infection. The masks were designed by Temple's very own Dr. David Brookstein, a professor in the College of Engineering. Dr. Brookstein's mask design includes two layers of cotton fabric with a protective sheet of filter paper in between. Constructing the masks does not require sewing skills; rather, volunteers who make them use a grommet machine to punch holes in the corners of the fabric, through which they run rubber band earpieces. This makes for an efficient, but protective design with simplicity of construction and ease of use. 
Brookstein's design was taken up by Dr. Kathleen Reeves and Prof. Nicolle Strand of LKSOM's Center for Urban Bioethics (CUB), who have over the years formed close partnerships with members of the North Philadelphia community through outreach and advocacy. When the pandemic first began, there was a great need in the community for fabric masks due to short supply, and CUB responded with enthusiasm. With funding and support from CUB, two fourth-year Temple medical students - Vittoria Boni and Kurt Koehler - joined the CUB initiative to spearhead the recruitment of over 120 volunteers from Temple Schools of Medicine and Public Health. And so Fabric Masks for North Philly was created. Koehler and Boni created week-long shifts during which volunteers picked up mask supplies from a central location on Temple's Health Sciences Campus, made masks in their homes, and returned their completed masks at the end of the week. Each volunteer typically made between 50-100 masks per shift.

\section{Our Interdisciplinary Approach}

The first student-managers of FMNP, Boni and Koehler, expanded the leadership team to include Meghan Swyryn--a second-year medical student--and Theresa McShea--a senior Undergraduate in the College of Public Health--after both students had shown exceptional commitment to FMNP as volunteers. By the summer of 2020, the team grew to include equally dedicated and creative volunteers: Michelle Liu (Public Health Undergraduate), Schyler Edwards (third-year medical student), and Brian Fertig (fourth-year Engineering Undergrad). Meghan Swyryn and Michelle Liu have managed all aspects of volunteer communication during weekly pickup of supplies and drop-off of finished masks. Schyler Edwards has served as our Community Outreach Coordinator, managing the communication between our team and our mask recipients. Additionally, she has arranged for pickup or delivery of the masks for each site. Theresa McShea and Brian Fertig have organized materials for weekly volunteer pickups on Temple's Health Sciences campus in addition to tracking mask inventory and preparation of orders for distribution. These members also assist in weekly deliveries for community sites.

Fortunately, motivated volunteers have been copious, with a large group of Public Health and Medical students passionate about getting involved in the COVID-19 response. With the generous support of Dr. Jennifer Ibrahim, Associate Dean of Academic Affairs in Temple University's College of Public Health (CPH), FMNP connected with hundreds of undergraduate students in $\mathrm{CPH}$. The initial outreach email in May secured more than $50 \%$ of the volunteers we have today. FMNP quickly gained momentum during the summer months, with several volunteers regularly signing up for weekly shifts. FMNP's volunteers have come from all walks of life, including Temple faculty, students in graduate and professional studies, undergraduates, and even professionals who are not affiliated with Temple University. Throughout the duration of the program, we have been fortunate to work with over 100 volunteers who are passionate about supporting the North Philadelphia community during the pandemic. As of December of 2020, the volunteers have collectively made over 13,000 face masks distributed to over 35 recipient organizations in North Philadelphia.

\section{Feedback from Our Community Partners}

In order to assess the continued need for the fabric masks, we asked some of our community partners for feedback on our program. Deborah Jowers from Zion Baptist Church shared: "Zion Baptist Church, as you know, has been a pillar in the community and neighbors of Temple for many years. Our current operations are following the CDC guidelines and so we are worshipping via Zoom and Facebook. We do, however, use face masks for the support staff of the church who do day-to-day work in the church. We appreciate the supply of masks provided to us by the [Temple] medical students which continues to 
help them remain safe. Amelia Price, Reverend Mike Majors and Reverend Jeff Harley are on our community outreach team (Called to Serve) who also utilizes the masks provided by Temple." Another one of our partners, Denise Robinson from Church of the Advocate told us: ".. with COVID-19, the only program currently running is our soup kitchen--also known as the Advocate Cafe. The masks have been a godsend as most of our patrons to the soup kitchen...cannot obtain a mask on their own. Secondly, they like that they are lightweight and not so snug-fitting that it makes it hard to breathe. We love the fact that we can help them and in doing so are protecting ourselves."

Our effort to create and distribute masks has helped our community partners to continue their work supporting the residents of North Philadelphia. These organizations could request masks for a single event or on a recurring basis as needed for their operations. Our team ensured that incoming orders were processed so that community sites would receive their masks on the dates requested. Some of our volunteers who helped create the masks even signed up to deliver orders to various locations throughout the city. Throughout the duration of our program, we have seen mask orders ranging in number from 12 to 800 in support of worship centers, schools, and community development organizations.

\section{Moving Forward}

With the current "second wave" of COVID shattering previous records for daily new cases, appropriate protection and social distancing are needed now more than ever to mitigate the spread of the virus. This ongoing need fuels our desire to continue distributing fabric masks in North Philadelphia. With our current resources and volunteer force, we are hoping to distribute a total of 15,000 face masks to the community by the end of December 2020. But more important than these numbers are the lives and livelihoods of our beloved community members that these masks hopefully play a small part in protecting.

For more information about Fabric Masks for North Philly and to support our cause, please visit our website at https://www.masksforphilly.com/.

\section{Disclosures and Conflicts of Interest}

The authors report no conflicts of interest.

\section{Funding Sources}

LKSOM Center for Urban Bioethics, LKSOM Temple Emergency Action Corps (TEAC), GoFundMe provided funding for the mask production process, but did not support the publication of this article.

\section{Statement of Contributions}

All authors contributed to the writing and editing of this manuscript. 